\title{
'n Skoolhoof se persepsies van die verwesenliking van Christelike waardes in 'n Suid-Afrikaanse laerskool: 'n Gevallestudie
}

\author{
Author: \\ Gertruida M. Steyn ${ }^{1}$ \\ Affiliation: \\ ${ }^{1}$ Department of further \\ education, University of \\ South Africa, South Africa \\ Correspondence to: \\ Gertruida Steyn \\ Email: \\ steyngm1@unisa.ac.za \\ Postal address: \\ PO Box 392, University of \\ South Africa 0003 \\ South Africa \\ Dates: \\ Received: 25 Aug. 2012 \\ Accepted: 06 June 2012 \\ Published: 05 Dec. 2012 \\ How to cite this article: \\ Steyn, G.M. 2012, "n \\ Skoolhoof se persepsies \\ van die verwesenliking van \\ Christelike waardes in ' $n$ \\ Suid-Afrikaanse laerskool: \\ 'n Gevallestudie', Koers \\ - Bulletin for Christian \\ Scholarship 77(2), Art. \#58, \\ 10 pages. http://dx.doi. \\ org/10.4102/koers.v77i2.58
}

C) 2012. The Authors. Licensee: AOSIS OpenJournals. This work is licensed under the Creative Commons Attribution License.
Vele Suid-Afrikaanse skole word uitgedaag om 'n skoolkultuur te vestig wat bevorderlik vir onderrig en leer is. ' $n$ Skoolkultuur het 'n baie groter impak op lewe en leer as enige ander faktor in 'n skool. Hierdie studie se navorsingsvraag is: Hoe het ' $n$ laerskoolhoof die verwesenliking van Christelike waardes in 'n skoolkultuur beskou? 'n Ondersoekende, kwalitatiewe navorsingsontwerp, in besonder 'n gevallestudie, is as die geskikste metode oorweeg om die navorsingsprobleem te benader. Doelbewuste steekproewe is gebruik vir die studie wat by die skool gedoen is. In vorige studies in die skool het ek aangetoon dat die deelnemer waarde aan die verwesenliking van Christelike waardes in die skool geheg het. Inligting in hierdie studie is deur semi-gestruktureerde onderhoude met die hoof versamel; paragrawe wat die hoof geskryf het (naïewe sketse); geskrewe dokumente oor die aktiwiteite in die skool; 'n DVD van die skool en veldaantekeninge wat tydens die onderhoude geneem is. Die bevindinge toon die rol wat die skoolhoof in die verwesenliking van waardes gespeel het en die noodsaaklikheid van 'n visie en missie om waardes te verwesenlik. Die realisering van waardes word die beste verwesenlik deur middel van 'n positiewe, uitnodigende skoolkultuur wat menslike ontwikkeling aanmoedig en op voortdurende groei fokus.

A principal's perceptions of the realisation of Christian values at a South African Primary School: A case study. Many South African schools are facing the challenge of establishing a school culture that is conducive to teaching and learning. The school culture has a far greater impact on living and learning than any other factor in the life of a school. The research question in this study is: How did a primary school principal view the actualisation of Christian values in the school culture? An investigative, qualitative research design, and more particularly a case study, was considered to be the most appropriate approach to the research question. In a number of previous investigations in the school, the author has shown that the school principal treasured the inculcation of Christian values in the school. Data in this study were collected by means of various semi-structured interviews with the principal; paragraphs written by the principal; documents about school activities; a DVD of the school; and field notes taken during the interviews. The findings show the role of the principal in inculcating values in a school and the effect of a vision and mission to realise these values. Inculcating values in a school is best actualised in a positive, inviting school culture that focuses on continuing growth conducive to human development.

\section{Inleiding}

Skole moet vele verskillende uitdagings die hoof bied. Skole moet onder andere 'n kultuur vestig wat onderrig en leer bevorder, hoë opvoedkundige standaarde stel en handhaaf, met ouers saamwerk, verandering en konflik bestuur, hulpbronbeperkings hanteer en sorg dat hulle aan hul onderskeie gemeenskappe verantwoording kan doen (Retna 2007; Vemić 2007; Vick 2004). Studies toon aan dat 'n skool se kultuur'n uitwerking op leerders se prestasie en sosio-emosionele welstand het (Marcoulides, Heck \& Papanastasiou 2005; Schoen \& Teddle 2008; School climate research summary 2007). Smith en Gillespie (2007:205) skryf die volgende: 'There is no doubt that the current educational climate is driven by an overriding concern with student achievement and what promotes it.'

Die onderrig- en leerkultuur in Suid-Afrikaanse skole is swak, en dit is bekend dat Suid-Afrikaanse skole 'n krisis beleef (Paton 2006:1; Bloch 2008:19) en in 'n baie onbevredigende toestand is (Bloch 2008:19). Suid-Afrikaanse skole voldoen nie aan die behoeftes van 'n ontwikkelende land nie en vaar oor die algemeen swakker in gestandaardiseerde geletterdheids- en wiskundetoetse as ander lande (Bloch 2008:19). 


\section{Konseptualisering en probleemfokus}

Akademici verskil oor die onderskeid wat tussen skoolkultuur en skoolklimaat getref word (Kruger 2003; Gruenert 2008; Jansen 2002; School climate and learning 2004; The Principals' Partnership 2006; School climate research summary 2007), maar hulle is dit eens dat elke skool 'n bepaalde identiteit het. Die identiteit gaan gepaard met gedeelde waardes en oortuigings wat die skoolgemeenskap saamsnoer, die standaard van prestasie beïnloed en wat 'n invloed op die gedrag en gesindhede van personeel het (Schoen \& Teddle 2008; Werner 2003). In die verband verduidelik Gruenert (2008) en Schein (1990) dat 'n organisasiekultuur ontwikkel wanneer ' $n$ groep mense ' $n$ aansienlike hoeveelheid tyd saam deurbring. Sullivan en Glanz (2006) verduidelik die standpunt soos volg:

Just as traditional societies pass on understandings of human beings, so too does our culture transmit, through the daily processes of living, interpretations of the world that shape our behaviour. (bl. 11)

Hierdie kultuur verteenwoordig die stel oortuigings en waardes van die organisasie, word beskou as die persoonlikheid van die organisasie en 'dictates its collective personality' (Gruenert 2008:57). In haar studie toon Hattingh (1991:98) aan dat waardes as kriterium dien in die rig van gedrag en in die ontwikkeling van houdings en gesindhede. Sy erken egter dat waardes situasiebepaald is en dat die eise van die situasie waarin die mens hom of haar bevind, bepalend kan wees vir sy of haar waardes of waardeprioriteite (Hattingh 1991:306, 338). Voorts huldig Van der Walt, Potgieter en Wolhuter (2010:155) die mening dat ' $n$ waardestelsel riglyne bied 'oor wat werd is om te verander, wat waarde kan verkry deur verandering' in organisasies.

Schein (1990) beklemtoon die volgende belangrike aspekte van 'n organisasiekultuur:

1. Die basiese aannames en oortuigings wat deur 'n gegewe groep ontwikkel of ontdek word namate dit leer om probleme of eksterne aanpassings en interne integrasie aan te spreek.

2. Die kulturele waardes wat goed genoeg gewerk het om as geldig beskou te word.

3. Die wyse waarop die kultuur by wyse van gedrag en artefakte manifesteer. (bl. 11)

As verbesondering van ' $\mathrm{n}$ organisasiekultuur bestaan 'n skoolkultuur uit die volgende komponente: waardes, bepaalde aannames en artefakte en simbole (School climate and learning 2004). Vir die doeleindes van hierdie studie word skoolkultuur omskryf as die gedeelde waardes, oortuigings, houdings en norme wat kenmerkend is van ' $n$ bepaalde skool (Kruger 2003:13; The Principals' Partnership 2006; Schoen \& Teddle 2008; Van der Westhuizen, Oosthuizen $\&$ Wolhuter 2008).

Volgens Sparks (2003) het 'n skool se kultuur 'n baie groter impak as enige ander faktor op die skoollewe en leer. Voorts dui studies aan dat uitnemende skole se oortuigings en waardes ' $n$ deurslaggewende rol in hulle produktiwiteit speel (Conway 1989:142; Gruenert 2008). Dit verklaar waarom suksesvolle skole 'n bepaalde stel waardes toon (Conway 1989:143). Die studie deur Marcoulides, Heck en Papanastasiou (2005) toon aan dat bepaalde kulturele prosesse in 'n skool tot die skool se kultuur bydra. In 'n vorige studie deur Marcoulides et al. (2005) is daar veronderstel dat 'n organisasiekultuur drie onderling verbonde dimensies het, naamlik 'n sosiokulturele stelsel bestaande uit die waargenome werking van die organisasie se take, strategieë en praktyke; die organisasie se waardestelsel en werknemers van die organisasie se kollektiewe houdings en oortuigings. In hierdie konteks kom die waardes en houdings en hul toepassing in 'n leerkultuur ter sprake (Doring 2002:7). In hierdie studie fokus ek op die manifestasie van 'n Christelike waardestelsel in ' $n$ bepaalde laerskool in Gauteng. Die sosiaal-kulturele faktore word bepaal deur die skoolhoof se persepsies van die skool se kultuurkapitaal en sy en die skool se oortuigings oor Christelike praktyke in die skool.

\section{Teoretiese raamwerk}

Aksieteorieë wat bestaan uit teorieë-in-praktyk en ondersteunende teorieë (espoused theories) (Argyris 1993; Argyris 1999; Howley \& Howley 2007; Osterman \& Kottkamp 2004; Sullivan \& Glanz 2006) kan aangewend word om 'n skool se kultuur te waardeer en te verstaan. Teorieë-in-praktyk is implisiet en bepaal en beheer die werklike gedrag, terwyl ondersteunende teorieë verwys na die woorde wat mense gebruik om die wêreldbeskouing en waardes waarop mense glo hulle gedrag gegrond is, uit te druk (Theory of Action: Theory-in-use and Espoused Theory n.d.). Sullivan en Glanz (2006:11) skryf die volgende oor teorieë-in-praktyk: 'Unlike espoused theories that develop through conscious and intentional thought, theories-in-use develop through acculturation.' Skoolhoofde ontwikkel dus teorieë-inpraktyk wat hulle in staat stel om daagliks hulle werk te doen (Howley \& Howley 2007:6) en hierdie teorieë-in-praktyk moet ondersoek word om te verklaar waarom 'n verskynsel soos ' $n$ bepaalde skoolkultuur ontwikkel het. Hierdie teorieëin-praktyk word deur middel van ondersteunende teorieë in woorde verduidelik om aan ander oor te dra wat hulle in die praktyk doen of wat hulle wil hê ander moet dink (Theory of Action: Theory-in-use and Espoused Theory n.d.).

Gesitueerde leer soos voorgestaan deur Wenger (2000; 2001; 2007) vorm nog 'n konseptuele grondslag vir die studie. Volgens Wenger (2000:229) is praktykgemeenskappe (communities of practice) die sosiale houers van bevoegdheid en ook die basiese boustene van 'n sosiale leerstruktuur. Wenger (2007:1) verduidelik soos volg hoe praktykgemeenskappe ontstaan: '(Communities of practice form when people) engage in a process of collective learning in a shared domain of human endeavour.' Volgens Wenger (2001:40) beskik praktykgemeenskappe oor die volgende sterk punte: die vermoë om strategieë deur te voer, probleme op te los en beste praktyke te bevorder. ' $n$ Gemeenskap is ' $n$ praktykgemeenskap as dit die volgende drie kenmerke het: 
1. Die domein: Lede van praktykgemeenskappe het belang by dieselfde domein (in hierdie gevallestudie is die domein Christelike waardes).

2. Die gemeenskap: Lede is saam betrokke by aktiwiteite, verleen hulp aan mekaar en deel hul kennis en vaardighede.

3. Die praktyk: Lede van'n praktykgemeenskap is praktisyns met 'n gedeelde praktyk wat ontwikkel het op grond van die wyse waarop hulle uitdagings die hoof bied.

\section{Navorsingsontwerp}

Die studie het ten doel gehad om lig te werp op die verwesenliking van bepaalde waardes in 'n laerskool in Gauteng, dus is daar besluit dat 'n verkennende, kwalitatiewe navorsingsontwerp die mees aangewese sou wees. 'A case study promotes better understanding of a practice or issue and facilitates informed decision-making' (McMillan \& Schumacher 2006:333). Die navorsingsprobleem is vanuit ' $n$ pragmatiese perspektief benader. Die studie sluit in die verkenning en beskrywing van 'n 'gebonde stelsel', 'n bepaalde laerskool in Gauteng (Creswell 2007:244; Fouché 2005:272; McMillan \& Schumacher 2006:26). Die studie probeer nie om gedrag in terme van universele wette te verklaar nie, maar om die betekenisse en bedoelings onderliggend aan alledaagse aksies en die toepassing van Christelike oortuigings te ondersoek.

Doelbewuste steekproefneming is gebruik in die studie wat by die skool uitgevoer is. Die navorser was sedert 1992 by 'n aantal studies by die skool betrokke (Steyn 1994; Steyn 2006; Steyn 2007; Steyn 2008; Steyn 2009; Steyn 2010) en het die skoolhoof se vertroue gewen. Tydens hierdie studies het die deelnemers getoon dat die skoolhoof waarde heg aan die skool se Christelike kultuur. Die betrokke laerskool in Gauteng het ongeveer 1400 leerders en 80 personeellede (onderwysers en administratiewe personeel), met 34 personeellede wat deur die Departement van Onderwys vergoed word. Die skool is in 'n gemiddelde tot bogemiddelde omgewing, maar sommige ouers sukkel finansieel.

Data is deur middel van semi-gestruktureerde onderhoude met die skoolhoof ingesamel, insluitende 'n onderhoud oor refleksiewe foto's wat deur die skoolhoof geneem is, 'n opvolgonderhoud om lede te kontroleer, 'n onderhoud om meer duidelikheid oor die skool se waardestelsel te kry, paragrawe wat deur die skoolhoof geskryf is (naïewe sketse), dokumente oor skoolaktiwiteite, 'n DVD oor die skool en aantekeninge wat gedurende onderhoude geneem is om die waarde en gehalte van die data asook die geloofwaardigheid en egtheid van die studie te verhoog (McMillan \& Schumacher 2006:374). Visueel-empiriese metodes word die afgelope jare aangewend in studies wat nie voorheen as visuele studies beskou is nie (Denzin \& Lincoln 2008; Harper 2008; Kassissieh \& Barton 2009; Zenkov \& Harmon 2009). Atkinson en Delamont (2008) voer aan dat daar baie sosiale verskynsels is wat in terme van hul manifestasie visueel vasgelê en ontleed kan word, soos ook in hierdie studie die geval is.
$\mathrm{Na}$ ' $\mathrm{n}$ 'foto-rondte' as inleiding tot die projek en instruksies oor die gebruik van die kamera (Zenkov \& Harmon 2009:577) is die skoolhoof van 'n laerskool in Gauteng versoek om ten minste 20 foto's met die navorser se kamera te neem. $\mathrm{Na}$ 'n week het hy refleksiewe foto's as deel van die data-insameling daargestel, maar daarby het hy ook by elke foto 'n paragraaf geskryf (naïewe sketse) om die foto te verklaar (Zenkov $\&$ Harmon 2009). Die skoolhoof het ook 'n onderwyser versoek om foto's van die 'ketelkamer' te neem (dit word later bespreek). Hy het aan 'n fotoverklaringsonderhoud deelgeneem (Harrington \& Schibik 2003; Harper 2008). Hy het ook 'n DVD getiteld 'In Hennops se voetspore - die kaalvoet-pret-prestasieskool' beskikbaar gestel. In hierdie DVD het die waardes van die skool duidelik na vore gekom. Die navorser het probeer om met behulp van die refleksiewe fotografie, die skoolhoof se naïewe sketse, die DVD, die drie onderhoude en die notas ondersoek in te stel na die skoolhoof se persepsies oor die manifestering van Christelike waardes in die skool. Die fotoverklaringsonderhoud het veral nuttige insigte oor die foto's se intrinsieke betekenis opgelewer. Die oogmerk was om 'n bespreking te ontlok, aangesien die skoolhoof sy eie ervarings deur middel van sodanige foto's kan beskryf (Schulze 2007). Twee opvolgonderhoude is gevoer om verdere duidelikheid te kry. Wat etiese sake betref, is die skoolhoof oor die doel van die navorsing ingelig, het hy toestemming gegee om daaraan deel te neem en is hy op ' $n$ menslike wyse hanteer (Creswell 2007). Die navorser het ook onderneem om na afloop van die studie terugvoering aan die skoolhoof te voorsien.

Die volgende hoofvraag is vir die doel van hierdie studie aan die skoolhoof gestel: hoe word die skool se karakter of waardes deur die foto's blootgelê? Die onderhoude is op band opgeneem en verbatim getranskribeer. Die navorsing is onderneem by die skool, wat in die deelnemer se natuurlike habitat is. Die navorser het die konkrete en presiese beskrywings van die skool se aktiwiteite in die transkripsies, notas, naïewe sketse en dokumente deurgelees en die DVD gekyk om 'beduidende stellings' (significant statements) (Creswell 2007:61) te identifiseer. Dié stellings verduidelik hoe die skoolhoof die skoolkultuur en die waardes wat met die skoolkultuur verband hou, ervaar. Beduidende stellings is toe gebruik om 'n beskrywing te bied van die skoolhoof se ervaring oor hoe hierdie waardes in die skool manifesteer. Dit was moontlik om die kern (Creswell 2007:62) van die verskynsel vanuit die beskrywing te identifiseer en die data het die volgende kategorieë opgelewer: die skoolhoof se leierskapsrol, die visie en missie van die skool: 'n positiewe, aantreklike skoolkultuur wat mense se ontwikkeling bevorder, asook 'n fokus op voortdurende groei. Aan die hand van 'n literatuurondersoek is ' $n$ maatstaf vir die vergelyking en teenstelling van die bevindinge van hierdie studie met ander bevindinge gestel (Creswell 2003).

\section{Bevindinge Die skoolhoof se leierskapsrol}

In antwoord op die vraag hoe die foto's die skoolhoof se toewyding aan die ontwikkeling van die skool weerspieël, het hy gesê dat hy ses jaar vantevore besef het dat hy gaan aftree en dat hy sy personeel verder moet bemagtig en 
ontwikkel. Hy het John Maxwell se 21 Laws of leadership gelees. Die eerste wet noem Maxwell 'the law of the lid'. Dié wet sê baie duidelik dat as die leier van 'n organisasie, skool of kerk 'n 4/10-leier is die organisasie, skool of kerk slegs 'n $4 / 10$ organisasie, skool of kerk sal wees. Hy is van mening dat indien die hoof nie groei nie, 'n plafon bereik sal word. Sy perspektief op sy eie ontwikkeling ter wille van die skool is reeds in 'n vroeër studie verduidelik (Steyn 2006):

I have always tried to pass it [leadership] off by saying that the principal is not that important. But after Maxwell's presentation my whole way of thinking changed ... And I have also committed myself even further to really developing my worthiness for leadership. (bl. 5)

Die oortuiging van die skoolhoof ondersteun die teorieëin-praktyk asook gesitueerde leer. Deur middel van die ondersteunende teorie, 'the law of the lid', het die skoolhoof sy teorie-in-praktyk verduidelik. Hy het duidelik aangetoon hoe belangrik dit is dat rolspelers, veral personeel, in die praktykgemeenskap bemagtig moet word.

Daar is reeds gemeld dat skoolhoofde teorieë-in-praktyk ontwikkel wat hulle in staat stel om hul daaglikse werk te verrig en om daardeur ' $n$ bydrae tot die vorming van ' $n$ skoolkultuur te lewer (Howley \& Howley 2007; Marcoulides et al. 2005). Deur personeel te bemagtig, ontstaan voorts 'n praktykgemeenskap waar personeel se kennis en vaardighede ontwikkel. Sonder doeltreffende leierskap kan pogings om die skoolkultuur te verander en onderwysers se toewyding te bevorder, waarskynlik nie slaag nie (Crum \& Sherman 2008; Ediger 2006). Dit is 'n sleutelfaktor wat ' $n$ skool se sukses of mislukking bepaal (Hale \& Moorman 2003; Hess \& Kelly 2005).

Oor die jare het navorsing, regeringsinisiatiewe en die praktyk bevestig dat leierskap 'n belangrike rol speel in die vestiging van 'n omgewing wat die gehalte van 'n skool en leerders se prestasie bevorder (Crow 2003; Vick 2004; Hammersley-Fletcher \& Brundrett 2005; Weindling 2003). Skoolleiers tree ook op as onderrigleiers as hulle 'n doeltreffende leeromgewing in skole skep, onderwysers mobiliseer en pogings aanwend om leerderprestasie te verbeter (Jabal 2006; McClay \& Brown 2003; Southworth \& Du Quesnay 2005; Vick 2004). Hulle het ook die potensiaal om personeel na hoër vlakke van doeltreffendheid te lei (Hess \& Kelly 2005), aangesien hulle rol op gemeenskaplike ideale gegrond is. Hulle kan ook die hoofvolgelinge wees wat 'n voorbeeld stel, ander leer en hulle help om beter volgelinge te word (McKerrow, Dunn \& Killian 2003:2).

Die eerste kenmerk van doeltreffende onderwysleiers is dat hulle die vermoë het om die visie, missie, prioriteite en persoonlike, professionele en organisatoriese waardes met die bepaalde konteks in die skool in ooreenstemming te bring (Jabal 2006; Hoy \& Smith 2007; Kassissieh \& Barton 2009).

\section{Die visie en missie: 'n Positiewe, aantreklike skoolkultuur wat mense se ontwikkeling bevorder}

Die skool se visie en missie word baie duidelik in die DVD uitgespel:
'Om die beste Afrikaanse laerskool in die wêreld te wees, waar elke leerling, ouer en personeel gelukkig is, en elke individuele leerling die geleentheid kry om sy unieke vermoëns optimaal te kan ontwikkel tot verheerliking van God' ... 'Ons as dinamiese skool wat verbind is tot uitnemendheid, ons leerlinge sal opvoed en inspireer om verantwoordelike, produktiewe en etiese lede van die gemeenskap te wees met die nodige vaardighede en passie om kreatief te dink, krities te redeneer, effektief te kommunikeer en deurlopend te leer. Ons sal dit bereik binne 'n opvoedkundige omgewing wat gekenmerk sal word deur hoë standaarde, asook 'n duidelike gedefineerde kurrikulum, wat deur voortreflike (beter as die beste) personeel in vennootskap met betrokke ouers en 'n wyer gemeenskap geïmplementeer word.'

Die behoefte om 'n leeromgewing te skep wat die ontwikkeling van leerders se potensiaal bevorder, gaan met die skool se visie en missie gepaard. Die skoolhoof het in 'n naïewe skets verduidelik hoe die 'Wees Positief'-teken (Be Positive: $\mathrm{B}+$ ), wat op verskeie plekke in die skool te sien is, ontstaan het. 'n Paar jaar gelede het 'n professor van Stellenbosch Universiteit 'n kursus aangebied (Steyn 2010).

Sy totale benadering was so positief van aard oor die land, die onderwys. Sy totale ingesteldheid as mens het hulle aangegryp. Dit het ons laat besef om dit die doel van die skool se uitgangspunt te maak, B+ (Be Positive). (bl. 252)

In een van die onderhoude het hy verduidelik dat dit hom ook self gemotiveer het en dat hy daarom die teken op verskeie plekke in die skool aangebring het om ander te motiveer (kyk na Figuur 1.)

Die B+-teken sluit ook die regte ingesteldheid teenoor die lewe in. Die skoolhoof het soos volg melding gemaak van die rol wat hy in die vestiging van positiewe houdings by rolspelers gespeel het:

'Ek het vir 'n hele jaar lank lesings oor gesindheid gegee ... Gesindhede kan jou lewe verander. ... Negatiewe mense versuur die hele omgewing. Hulle is eintlik vrot appels... Die groot oorlog is in jou kop. Die hele ding van attitude begin van binne: wat kies jy in die lewe ... Ek het baie gelees en ook weekliks in nuusbriewe geskryf vir kinders oor gesindhede.'

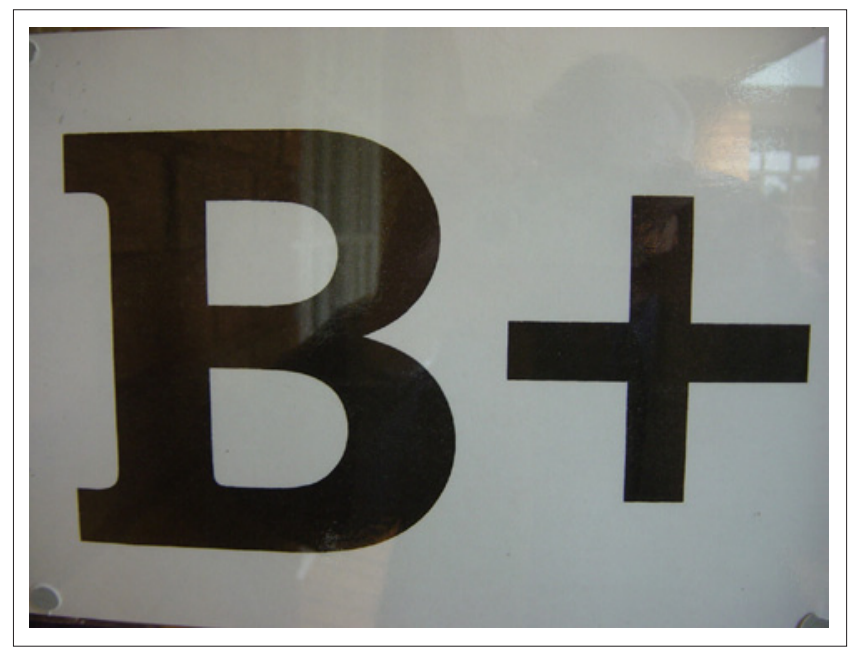

FIGUUR 1: Wees positief. 
Elke skooldag begin met voorlesing uit die Bybel, 'n Christelike lied en gebed. Die 'ketelkamer' is nog 'n voorbeeld van die wyse waarop Christelike waardes in die skool bevorder is: In dié vertrek het leerders en personeel die geleentheid om God te eer, te verheerlik en te prys, om saam te bid (kyk na Figuur 2) en om 'tyd vir God in te ruim', om 'vreugde in die Here te vind' en om 'God in jou hart in te nooi', soos tekeninge wat kinders in die 'ketelkamer' gemaak het, aantoon. ('n Voorbeeld van so 'n tekening verskyn in Figuur 3.) Die skoolhoof het gesê dat as hy 'n tema vir die skool kon kies, dit 'Aan Hom al die eer' sou wees. Hy het ook melding gemaak van Ps 127:1 (1983-vertaling) ter ondersteuning van sy standpunt: 'As die Here die huis nie bou nie, swoeg dié wat daaraan bou, tevergeefs.'

Die skool het in 1993 'n toekenning van die International Alliance for Invitational Education gekry omdat dit 'n uitnodigende skool is (Figuur 4). Die ontwikkeling van 'n positiewe ingesteldheid is dus ook in ooreenstemming met die skool se verwesenliking van uitnodigende onderrig. Die grondslag van uitnodigende onderrig is bepaalde sleutelaannames oor die oordrag van liefdevolle, gepaste boodskappe wat daarop gemik is om die ontwikkeling van menslike potensiaal te bevorder. Dit dien as ' $n$ rigtinggewende teorie in die skool se ontwikkeling (Kok \& Van der Merwe 2002). Die eerste aanname in die besonder verklaar dat mense bevoeg, waardevol en verantwoordelik is en dienooreenkomstig behandel moet word (Purkey \& Aspy 2003; Schmidt 2004).

Die bevindinge ondersteun aksieteorieë, aangesien dit aantoon hoe die skoolhoof doelbewus daarna gestreef het om 'n positiewe, uitnodigende en Christelike skoolkultuur te skep waarin die visie en missie uitgeleef kan word. Dit ondersteun ook gesitueerde leer omdat talle geleenthede in die skool geskep is om rolspelers deel van die sosiale leerstruktuur te maak.

Navorsers is dit eens dat 'n gemeenskaplike visie en missie geskep moet word alvorens beleide, prosedures en strategieë ontwikkel kan word om die skool se doelwitte te bereik (Pankake \& Moller 2003; Hoy \& Smith 2007; Kassissieh \& Barton 2009; Sternberg 2005; Vick 2004:26). Pankake en Moller (2003:7) maak die volgende stelling: '[An] effective vision presents a credible yet realistic picture of the organization that inspires the participants to reach for a future goal.' As kollegas gemeenskaplike waardes het wat tot die vorming van praktykgemeenskappe bydra, ontstaan 'n kollektiewe verbintenis tot of toewyding aan die skool (Wenger 2007). Ten einde 'n gedeelde visie en missie te ontwikkel, moet 'n mens die vaardighede hê om gedeelde toekomsbeelde te identifiseer, want dít bring ware toewyding mee (Senge 1990:9). So 'n visie en missie het die vermoë om personeel te besiel; dit bevorder innovering en eksperimentering. As personeellede saam daarna streef om die visie en missie te verwesenlik, as hulle betrokke is by gemeenskaplike aktiwiteite en as hulle gedeelde belangstellingsdomeine het, ontstaan praktykgemeenskappe, soos Wenger (2000; 2001; 2007) verduidelik.

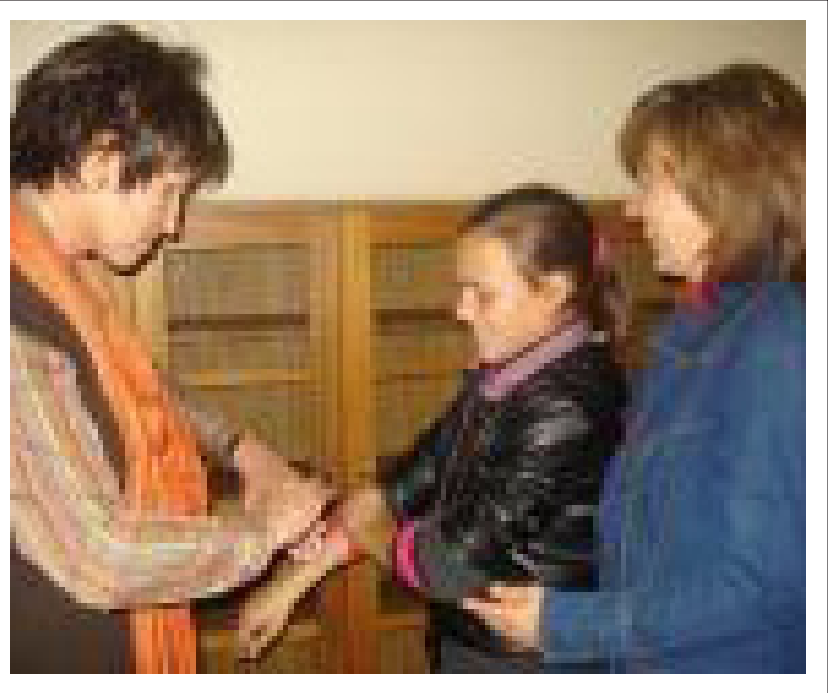

FIGUUR 2: Gebed in die 'ketelkamer'.

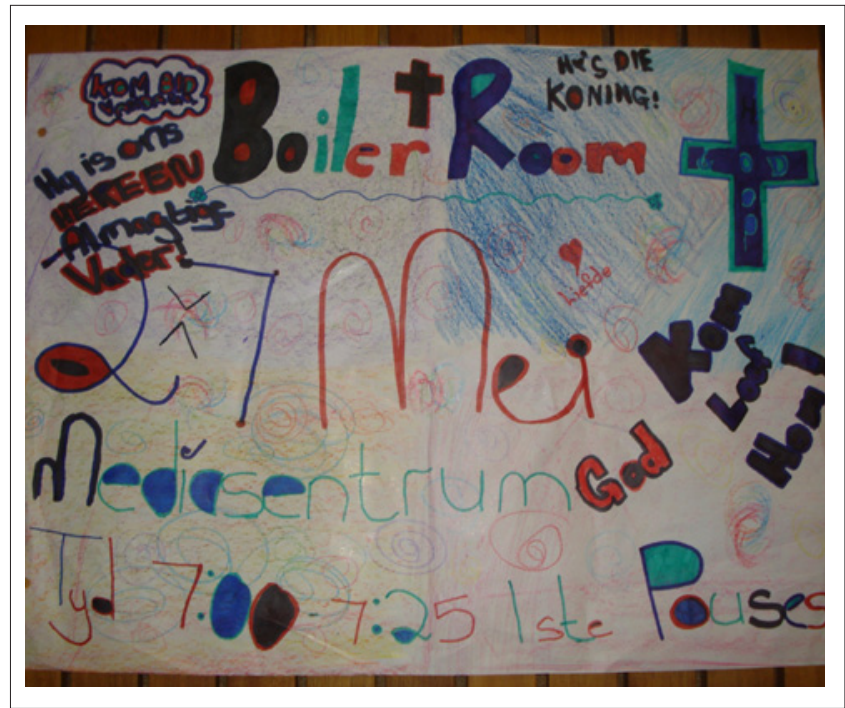

FIGUUR 3: Nooi God in jou hart.

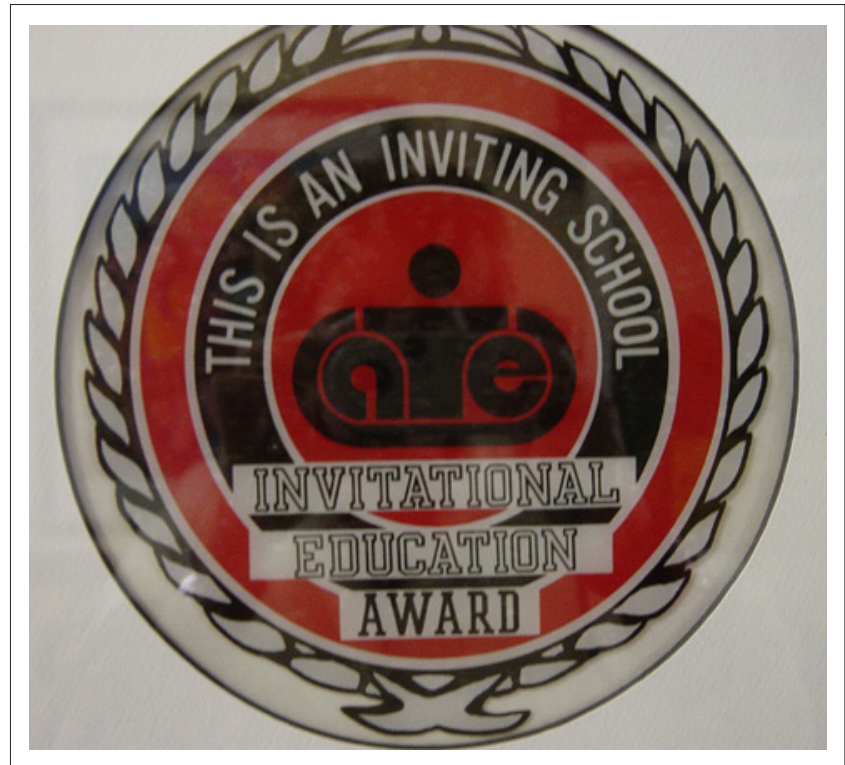

FIGUUR 4: Die uitnodigende skooltoekenning. 
'n Skool se visie- en missiestelling word op verskillende maniere verwesenlik. In hierdie artikel word gefokus op twee artefakte (die skoolwapen en die 'vrug van die Gees') en waardes en aannames (soos 'n fokus op mense, die ontwikkeling van leiers, die bearbeiding van oortreders en 'n fokus op volgehoue groei; School climate and learning 2004) wat die skool se Christelike karakter geopenbaar het.

\section{Artefakte in die skool}

Vir die doel van hierdie studie word daar kursories gekyk na die skoolwapen en die 'vrug van die Gees' as voorbeelde van artefakte in die skool waardeur die Christelike waardes verwesenlik is. Volgens die DVD simboliseer die driehoek op die skoolwapen afhanklikheid van en geloof en vertroue in God die Skepper. Dit is ook 'n simbool van groei. Die skoolhoof het in sy verduideliking van die simboliek van die skoolwapen gesê:

'Die hele wapen dui daarop dat dit 'n Christenskool is. Die kurrikulum moet God wees, Hy moet die middelpunt wees. As ek ' $n$ tema vir die skool moet kies is dit "To Him be the glory". Die puntjies onder die kiemplantjie sprei uit tot by 'n breër oppervlakte aan die bokant - wat sê "Streef hoog".'

Die twee kleure op die wapen het verskillende betekenisse: blou simboliseer die kleur van die hemel en goud dui op die son, die primêre energiebron. Die jong blare simboliseer jong kinders wat gedy as hulle deur die son gevoed word. Die horisontale lyne stel die aarde voor wat die takke lewend hou. Die lyne simboliseer ook die bepaalde rivier wat deur die gebied vloei.

Die skoollied se woorde is gegrond op die skoolwapen; dit toon jong plante wat op die aarde verbou word, uitstrek onder die blou lug en groei, sterk word en vrug dra: liefde vir die naaste, diensbaarheid aan die land en die volk en eer aan God as die hoogste pand. Let op die laaste woorde van die skoollied 'Ons streef hoog, ons streef hoog':

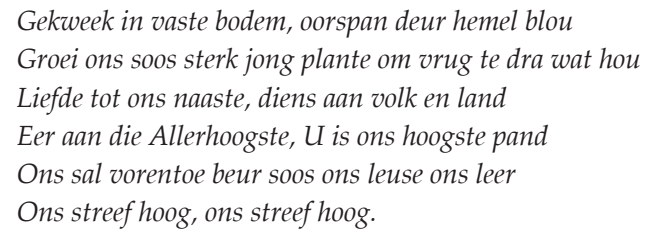

'n Tweede voorbeeld van 'n artefak in die skool is die 'vrug van die Gees'. Tydens die fotoverklaringsonderhoud met die skoolhoof het dit geblyk dat die idee van die 'vrug van die Gees' aanvanklik deur 'n ouer van een van die leerders geopper is - dit handel oor die fontein van liefde (Figuur 5). Hy het dit soos volg verduidelik:

Dis baie belangrik om waardes by kinders in te skerp, waardes soos liefde, vriendelikheid, nederigheid, netheid ... Mense is so ingestel op akademie wat hulle waardestelsels verwaarloos. Vat byvoorbeeld Nelson Mandela, hy was 'n ongelooflike leier met 'n ongelooflike waardestelsel. ... Die kern van baie goed is waardesisteme, trots, respek, liefde, nederigheid. Daarom is ons sterk gefokus op waardes in die skool. Die waardestelsel wil leerders voorberei vir suksesvolle plek in samelewing. Selfs by prysuitdelings ontvang leerders toekennings vir sulke waardes wat hulle uitleef, soos vriendelikheid, of hardwerkendheid of goeie maniere of netheid.

Die leerders ontvang nie in die derde kwartaal 'n akademiese rapport nie. Hulle ontvang egter 'n handgeskrewe rapport van die onderwysers met positiewe inligting oor die kind en aspekte wat verband hou met die waardes wat leerders geopenbaar het. Elke onderwyser moes slegs een goeie eienskap van die kind neerskryf. Die skoolhoof het die geskiedenis van hierdie stelsel uitgelê:

Dit [vrugte van die gees] het eintlik ontstaan deur 'n klas in Amerika. Die onderwyser het gesê hulle moet almal iets moois skryf oor ander kinders in die klas. Toe het sy al die mooi eienskappe saamgevat en vir elke kind sy mooi goed gegee ... In Viëtnam skiet hulle een seun dood en toe kry hulle in sy sak die rapport wat sy juffrou en maats vir hom gegee het. Toe besef ons net dat mense so min mooi goed oor mekaar sê. Ons is so geneig om op die lelike goed te konsentreer. Toe het ons besluit om so 'n positiewe verslag vir die kind te gee.

Die twee artefakte toon hoe sekere teorieë-in-praktyk wat uit die visie en missie in die skool voortspruit, verwesenlik is. Die skoolhoof se ondersteunende teorieë kom in die bevindinge duidelik na vore. Die bevindinge ondersteun ook gesitueerde leer deurdat 'n uitnodigende skoolkultuur die toewyding van alle rolspelers verlang. So ook word personeel en leerders in die vestiging en die vaslegging van waardes betrek. Dit is uit die skoolwapen en die 'vrug van die Gees' duidelik dat daar 'n sterk fokus op die mens is.

\section{'n Fokus op mense}

Alle rolspelers in die skool word na waarde geag, insluitende leerders, personeel, ouers en selfs lede van die gemeenskap. Die skool fokus veral op sy leerders. Die skoolhoof het gesê: 'Die kinders moet gelukkig wees. ... Jy moet altyd mooi dink as jy besluite neem: is dit in belang van die kind of is dit in belang van my?' Volgens hom moet kinders gelukkig wees en hulle geluk moet altyd 'n bepalende faktor by die besluitneming in die skool wees. Hy het die volgende op die DVD gesê: '[Dit is ' $n$ ] onbeskryflike voorreg om met weglopertjies uit die hemel te werk' (Steyn 2010:253). Die skool se fokus op mense kom onder andere in die volgende voorbeelde na vore.

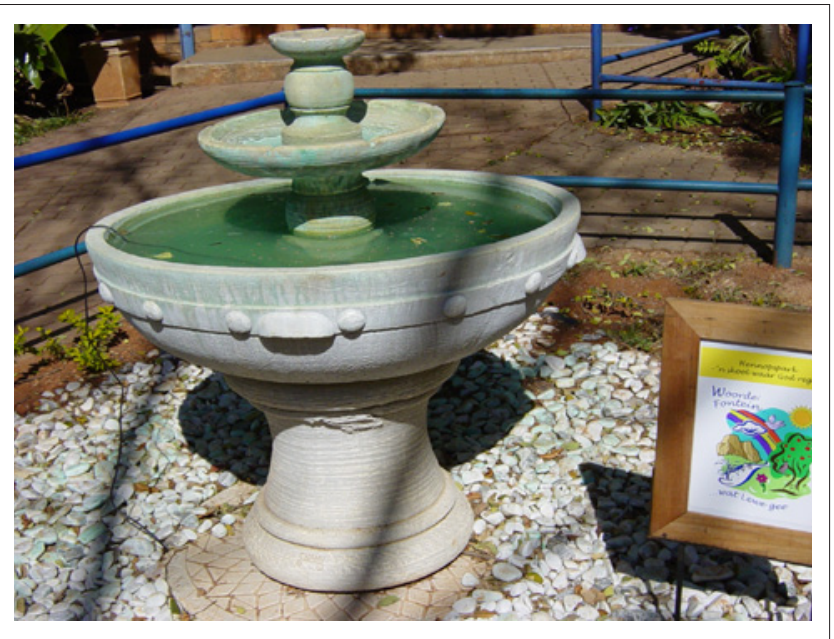

FIGUUR 5: Die fontein van liefde: Vrug van die Gees. 


\section{Kweek 'wenners'}

God het met Christus se koms na die wêreld sy liefde vir mense bewys. Hy wil ook sy uitverkore kinders meer as oorwinnaars maak om Sy koninkryk te bevorder. Die skool se fokus op mense kom in besonder na vore in hulle benadering om 'wenners' te kweek. Die skoolhoof het in 'n naïewe skets die skool se paradigmaverskuiwing met betrekking tot beloning verduidelik (Steyn 2010):

Tydens prof. Olivier se besoek het hy iets gemeld wat 'n paradigmaskuif in ons skool se benadering tot die beloning van leerders teweeggebring het. Hy het by 'n spesifieke skool in die VSA (blykbaar is dit meer algemeen daar) opgemerk dat feitlik die hele skool (veral laerskole) pryse ontvang. Dit het radikaal verskil van ons benadering waar net 'n paar uitstaandes op die verhoog verskyn. By verdere navraag oor hoekom hulle dit doen, het hulle gesê hulle wil WENNERS kweek. By ons prysuitdelings kry feitlik 100\% van die leerders toekennings wat ook eienskappe van waardesisteme insluit soos vriendelikheid, hulpvaardigheid, netheid, liefdevol, ensovoorts. (bl. 254)

Tydens die fotoverklaringsonderhoud het die skoolhoof melding gemaak van die vorige stelsel by die skool, die 'swartlêerstelsel' (Steyn 2010). Dié stelsel het hoofsaaklik berus op straf soos hy verduidelik het:

Ons het voorheen 'n swartlêerstelsel by die skool gehad en ons het net hard gewerk ... Toe het ons net heeltemal wegbeweeg... En dit gaan nie werk nie as die kinders dit sien as 'n negatiewe ding waar hy gestraf word. [Die voorbeeld is aan die navorser getoon Figuur 6]. Jy kan die hele lêer vat [die blou- en oranjekaartselsel], die meeste inskrywings in ' $n$ klas is positief. Daar is min aan die oranje kant. 96\%, 97\% van die kinders het net inskrywings in die blou kant. Die kinders werk daarvoor. Alle mense wil net'n klop op die skouer hê, selfs ek wat al 65 jaar oud is. (bl. 254)

'n Vriend van die skool het jare gelede, ná 'n besoek aan Disneyland, vertel dat die werknemers by Disneyland hul toekennings uitstal en baie trots is daarop. Dit het die skool aangespoor om 'n beloningstelsel wat op die Disneylandstelsel geskoei is, in werking te stel. As leerders sewe stempels op 'n sertifikaat gekry het, kan hulle 'n diploma vir uitstekende werk kry. Na die sewende stempel is 'n brief van gelukwensing met die kind se wonderlike prestasie aan die ouers gestuur.

Die positiewe skoolkultuur word duidelik uit enkele van die toekennings wat vir die versterking van positiewe gedrag aan rolspelers gegee word.

- Ysterwapen: Die skool gee erkenning aan personeellede en leerders deur 'n ysterwapen aan hulle toe te ken.

- Diploma vir onderwyser: Die skoolhoof het verduidelik dat kollegas 'n aanbeveling skryf vir 'n onderwyser wat iets buitengewoons gedoen het. Ná drie aanbevelings ontvang so 'n onderwyser 'n diploma.

Dis wanneer iemand die tweede myl loop, iemand wat iets uitsonderlik gedoen het ... Enige onderwyser kan iemand aanbeveel en dit by my kom aanteken. Ek maak dit ook nie bekend wie die onderwyser aanbeveel het nie. As hy dan drie sulke aanbevelings het, dan kry hy 'n toekenning ... Ons wil vir ons personeel ook darem iets gee.

- Ysterwapen vir leerders: Die skoolhoof het verduidelik hoe leerders hierdie toekenning kon kry:
Volgehoue deelname is belangrik. Dit gaan glad nie oor prestasie nie - met deelname op akademiese, sport of kultuur gebied kan hulle punte behaal. Kinders moet aan die einde van die jaar ' $n$ vorm voltooi met alles waarin hulle deelgeneem net... Dit werk op 'n puntebasis. Wanneer hulle 12 punte gekry het, kry hulle 'n yster-lapelwapen. Leerders kom in aanmerking vir 'n brons, silwer of goue ysterwapen. Daar is egter ook ' $n$ 'remskoen'-vorm vir mense wat nie hulle kant bring nie. Dit gebeur baie min.

- Skild: Die leerders kan ook beloon word met die toekenning van 'n skild as hulle medemenslikheid geopenbaar het. Die skoolhoof het verduidelik:

Dis 'n toekenning wat hulle vir 'n week kan hou vir iets uitsonderlik wat hulle gedoen het, soos iemand wat in 'n wedloop val en iemand help hom op. Ons gee dit nie gereeld nie, dis vir iets uitsonderliks.

- Ander belonings: Die skool gee ook erkenning aan ander rolspelers wat besonderebydraes lewer. Ouers, grootouers en ander persone wat buitengewone diens gelewer het, kom in aanmerking vir ' $n$ eremedalje. Daar is ook ' $n$ Vriend van die Skool-toekenning wat op prysuitdelings of tydens bestuursvergaderings oorhandig word.

Gedragsverandering is een van die algemeenste maniere wat gebruik word om mense se gedrag positief te verander (Anonymous 2009; DuBrin 2009; Gerson \& Gerson 2006). Dit is gegrond op die wet van gevolge: Gedrag wat genotvolle en positiewe gevolge inhou, is geneig om herhaal te word, maar gedrag wat slegte en negatiewe gevolge inhou, is geneig om nie herhaal te word nie. DuBrin (2009:204) sê die volgende oor positiewe versterking: '[It increases] the probability that behavior will be repeated by rewarding people for making desired responses.' Daarby behels die Pygmalion-effek die volgende: As mense raaksien dat leerders ' $n$ talent het, demonstreer leerders daardie talent dienooreenkomstig (Riner 2003). In wese beteken gedragsverandering ook dat strategieë ingespan word om 'n einde aan onaanvaarbare gedrag te maak.

\section{Bearbeiding van 'oortreders'}

Daar moet besef word dat leerders ook menslik is en dat hulle dikwels dissipline nodig het om hulle op die regte koers te hou. Die wyse waarop dit gedoen word, openbaar 'n liefde

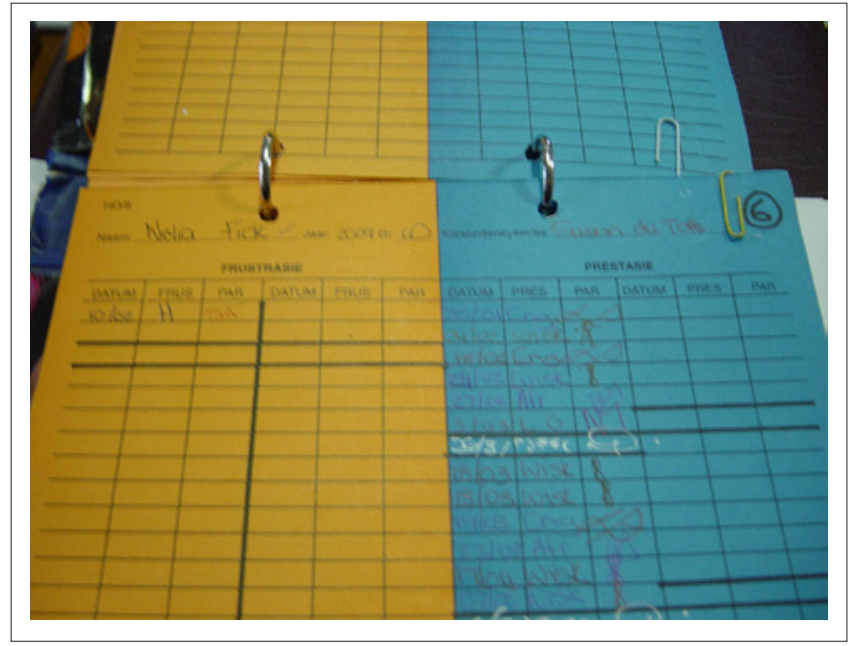

FIGUUR 6: Die blou- en oranjekaartstelsel. 
vir kinders en vergifnis van oortredings. Dit is soos volg deur die skoolhoof verduidelik:

Die ouens sal dink die skool het nie genoeg dissipline nie, dit sal die indruk skep. Ons het tog 'n goeie stelsel hoe ons met die belhamels, die 'culprits' werk. Ek het 'n kind in my kantoor gehad en hy het al sy finale waarskuwing gehad. Ek het sy pa gebel en gesê ons gaan hom 'n week uit die skool uitsit. Ons gaan hom skors. Hy moet net vir 'n week tot rus kom. En voor die ouer het ek vir hom vasgehou en vir hom gesê, 'Ek is baie lief vir jou. Maar jy kan nie aangaan met wat jy doen nie. Ons kan nie dit toelaat nie.' Hy het aan die einde van die jaar vir my kom dankie sê, nie my hoofleiers nie. Dit gaan oor hoe 'n mens met mense werk.

In 'n derde voorbeeld van die skool se fokus op mense word daar gekyk na hoe hulle hulle sosiale verantwoordelikheid probeer nakom.

\section{Sosiale verantwoordelikheid teenoor 'n skool in 'n agtergeblewe gemeenskap}

Die skoolhoof en personeel het ná 'n praatjie deur die akteur in die film 'Knights of the South Bronx' tot die besef gekom dat hulle wat 'baie het en weet', 'n groot veranwoordelikheid het om dit met ander te deel. Wat die skoolhoof veral getref het, is die feit dat die man nie 'n Christen was nie en tog soveel vir ander omgegee het. Dit was ' $n$ groot aansporing vir hom as Christen om ook die skool se sosiale verantwoordelikheid teenoor minderbevoorregtes uit te leef.

In een van die onderhoude het die skoolhoof verduidelik hoe die skool hulle verbintenis tot liefde vir die naaste uitleef: Die skool is die afgelope paar jaar betrokke by ' $n$ benadeelde skool in Mamelodi. Hyself het sy verbintenis bewys om self te help om bome op die skoolterrein te plant. Die twee skole het gereeld kruiskulturele kontak met mekaar, want albei is homogene skole.

'Ons is amper soos broers, soos ' $n$ groot familie. Ons doen vir hulle personeelontwikkeling, en kry self kundiges om hulle by die skool toe te spreek. Ons kry ook skenkings en borge vir die ontwikkeling van die skoolgeboue ... Die skool het ook 'n 'Angels' projek waar hulle kruideniersware en vleis vir minderbevoorregtes voorsien ... Ek wens ek kan jou vertel van die ongelooflike werk waarmee kinders besig is. Ons sosiale komitee samel kos vir arm mense en klere vir die winter in. Kinders kom met die interessantste en oorspronklike idees na vore.'

Deur middel van ondersteunende teorieë het die skoolhoof aangetoon hoe die skool op verskeie maniere probeer om wenners te probeer kweek, 'oortreders' te hanteer en die skool se sosiale verantwoordelikheid na te kom (teorieëin-praktyk). Die bevindinge toon ook hoe dit die fokus op kollektiewe leer (praktykgemeenskappe) onder alle rolspelers probeer bevorder.

Die eerste aanname van uitnodigende onderrig, naamlik dat mense waardevol, bevoeg en verantwoordelik is en dienooreenkomstig behandel moet word (Purkey \& Aspy 2003; Schmidt 2004:27), bevestig hoe belangrik dit is om mense na waarde te ag (soos Christelike waardes vereis). Alhoewel die Christelike waardes wat in die skool verwesenlik word prysenswaardig is, is menslike groei en ontwikkeling 'n natuurlike verskynsel. Dit impliseer dat die skool ook voortdurend sy praktyke moet verbeter en moet aanhou groei sodat stagnering nie voorkom nie.

\section{'n Fokus op volgehoue groei}

Voortgesette groei en ontwikkeling in die skool is vir die skoolhoof van die allergrootste belang. Daarom is die punt 'Verandering ter wille van verbetering' weekliks op die skoolbestuursvergadering se agenda. Hy het verduidelik:

Baie mense en organisasies lê begrawe met die volgende opskrif op die grafsteen: STATUS QUO. Dit is amper so fataal soos wanneer ons gewen het, om tot stilstand te kom en te lank fees te vier - uitnemendheid is dan reeds ' $n$ paar kilometer terug. Tiger Woods was na een van sy suksesvolle toernooie nie by die prysuitdeling nie. Toe daar gevra is waar is hy, het hulle gesê dat hy besig is om te oefen aan ' $n$ paar plekke waar hy gesukkel het.

Die volgende het in een van die skool se dokumente verskyn:

Uitnemendheid by $X$ (naam weerhou) lê nie net in ons roemryke tradisie nie, wat verby is, is verby. Dit dien as aansporing, ja, maar as ons op die standbeelde leun sal ons moet toesien hoe ander ons verbygaan en die louere inpalm. Ons kan uiteindelik as bedelaars langs die pad gaan sit en ander beny. Uitnemendheid is beslis nie maklik nie, dit vra energie, dissipline en toewyding: BLOED - SWEET -TRANE (John Short).

Die uitleef van Christelike waardes in die skool het voortdurende veranderinge vereis om 'n skoolkultuur te skep wat selfs nog doeltreffender is. Volgens die skoolhoof is dit 'n doelbewuste besluit (ondersteunende teorie) dat die skool voortdurend moet verander en voorbeelde soos wat uit die bevindinge na vore gekom het, ondersteun teorieë-in-praktyk. Verandering impliseer verder dat die hele skoolgemeenskap hierby betrokke moet wees, soos wat Wenger se gesitueerde leer en praktykgemeenskap voorhou. Die skoolhoof se standpunt oor die behoefte aan voortdurende ontwikkeling word deur die literatuur bevestig (Crum \& Sherman 2008; Gokçe 2009; Richardson 2003). As skole daarin wil slaag om 'n omgewing te skep wat verhoogde leerderprestasie bevorder, moet hulle'n skoolkultuur ontwikkel wat die klem lê op voortdurende groei sodat leertoestande geskep word wat tot alle leerders se voordeel strek (Bernauer 2002).

\section{Slot}

In hierdie studie is daar aangetoon hoe 'n skoolhoof die verwesenliking van Christelike waardes in sy skool beskou. Uit die bevindinge blyk dit duidelik dat die skool daarin geslaag het om Christelike waardes in die skool te verwesenlik. In die skoolhoof se verduideliking van die vestiging van 'n waardestelsel kom sowel ondersteunende teorieë as teorieëin-praktyk na vore. Dit is ook deurgaans duidelik hoe alle rolspelers deur middel van 'n praktykgemeenskap by die vestiging van Christelike waardes betrek is. Die onderstaande waardes word in die skool uitgebeeld:

- Behandel ander mense met respek: Wanneer dit gedoen word, word ' $n$ voorbeeld vir die uitlewing van bepaalde 
waardes gestel. Volgens die hoof slaag die skool daarin om respek te betoon aan rolspelers, onder andere deur erkenning te gee aan die bydraes wat hulle gelewer het. Daar word ook waarde geheg aan kinders se belangrikheid, hulle potensiaal en die ontwikkeling van hulle potensiaal.

- Stel 'n voorbeeld. Die skool heg baie waarde aan die 'voorlewing' van bepaalde waardes. Dit word visueel deur die fontein op die skoolterrein uitgebeeld (Figuur 5). Die vestiging van waardes word aangemoedig deur rapporte in die derde kwartaal en verskeie beloningstelsels. Die waardes sluit onder andere waardes soos liefde, vrede, geduld, vriendelikheid, goedhartigheid, nederigheid en selfbeheersing in.

- Behou 'n positiewe ingesteldheid. Die belangrikheid van 'n positiewe ingesteldheid teenoor die lewe is 'n onlosmaaklike deel van 'n gevestigde Christelike waardestelsel in die skool (Figuur 1).

- Verleen hulp aan minderbevoorregtes: Die skool is op vele terreine baie voorspoedig en glo dat dit 'n maatskaplike verantwoordelikheid teenoor die armes en minderbevoorregtes het.

- 'n Strewe na voortdurende groei: Voortdurende groei en ontwikkeling is van baie groot belang vir die laerskool. Volgens die hoof sou die laerskool tot niet gaan as dit sou stagneer. Die Bybel ondersteun by implikasie ook die idee dat mense moet groei.

Dit is noodsaaklik dat skoolgemeenskappe die belangrikheid van waardes moet raaksien, maar dit is slegs die wegspringplek. Om 'n skoolkultuur te vestig, moet toestande geskep word wat waardes ondersteun en struktuur daaraan verleen. Die studie ondersteun die beskouing van Pankake en Moller (2003:9) dat kulturele faktore wat 'n stabiele, betekenisvolle kultuur skep, die volgende insluit: onderwysers se deurlopende positiewe ingesteldheid, 'n fokus op leerders, norme en waardes wat voortdurende leer en ontwikkeling moontlik maak en nie bloot die status quo handhaaf nie, 'n gemeenskaplike, gedeelde visie en missie en 'n bewustheid van die verantwoordelikheid vir leerders se leer, welstand en sukses.

\section{Erkenning \\ Mededingende belange}

Die outeur verklaar dat sy geen finansiële of persoonlike verbintenis het met enige party wat haar nadelig of voordelig kon beïnvloed in die skryf van hierdie artikel nie.

\section{Literatuurverwysings}

Anon., 2009, '10 elements every high school should have in place', The Education Digest 74(9), 49-52, viewed 12 August 2009, from http://0-proquest.umi.com. oasis.unisa.ac.za/pqdweb?index $=0 \&$ did $=1742031411 \&$ SrchMode $=2 \&$ sid $=1 \& \mathrm{Fmt}$

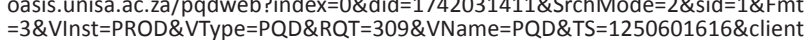
$=3 \&$ VInst $=$.
$I d=27625$.

Argyris, C., 1993, 'Teaching smart people how to learn', in R. Howard \& R.D. Haas (eds.), The learning imperative: Managing people for continuous innovation, pp. 177-194, Harvard Business School Publishing Corporation, Boston.

Argyris, C., 1999, On organizational learning, 2nd edn., Blackwell Business, Oxford.

Atkinson, P. \& Delamont, S. (eds.), 2011, SAGE Qualitative Research Methods, Sage Publications, Inc., London.

Bernauer, J., 2002, 'Five keys to unlock continuous improvement', Kappa Delta Pi Record 38(2), 89-92.
Bloch, G., 2008, 'SA in the midst of an education crisis', The Star, Thursday, 31 July, p. 19.

Conway, J.A., 1989, 'A perspective on organizational cultures and organizational belief structure', in J.L. Burden (ed.), School leadership: A contemporary reader, pp. 142-158, Sage, Thousand Oaks.

Creswell, J.W., 2003, Research design, 2nd edn, Sage, Thousand Oaks.

Creswell, J.W., 2007, Qualitative inquiry and research design: Choosing among five approaches, 2 nd edn, Sage, Thousand Oaks.

Crow, G.M., 2003, 'School leadership preparation: A short review of the knowledge base', viewed 04 August 2006, from http://www.ncsl.org.uk/media/93C/03/ school-leader-preparation.pdf

Crum, K.S. \& Sherman, W.H., 2008, 'Facilitating high achievement: High school principals' reflections on their successful leadership practices', Journal of Educational Administration 46(5), 562-580.

Denzin, N.K. \& Lincoln, Y.S., 2008, Collecting and Interpreting Qualitative Materials, Thousand Oaks, Sage Publications, California.

Doring, A., 2002, 'Lifelong learning for teachers: Rhetoric or reality?', Challenging futures? Changing agendas in teacher education. Armidale, New South Wales, 3-7th February, viewed 17 August 2008, from http://scs.une.edu.au/CF/Papers/ pdf/ADoring.pdf.

DuBrin, A.J., 2009, Human relations: Interpersonal job-oriented skills, 10th edn., Pearson Education International, Upper Saddle River.

Ediger, M., 2006, 'Administration of schools', College Student Journal 40(4), 846-852, viewed 17 August 2009, from http://0proquest.umi.com.oasis.unisa.ac.za/pqdwe b?index $=22 \&$ did $=1316225341 \&$ SrchMode $=2 \&$ sid $=9 \& \mathrm{Fmt}=3 \& \mathrm{VInst}=$ PROD\&VTyp e=PQD\&RQT $=309 \&$ VName $=P Q D \& T S=1249386038 \&$ clientld $=27625$

Fouché C.B., 2005, 'Qualitative designs', in A.S. De Vos, H. Strydom, C.B. Fouché \& C.S.L. Delport (eds.), 3rd edn., Research at Grass Roots, pp. 267-273, Van Schaik, Pretoria.

Gerson, R.F. \& Gerson, R.G., 2006, Effort management, Training and Development $60(6), 26-27$, viewed 06 July 2009, from http://0-proquest.umi.com.oasis.unisa. ac.za/pqdweb?index $=2 \&$ did $=1061991131 \&$ SrchMode $=2 \&$ sid $=2 \& \mathrm{Fmt}=2 \& \mathrm{VInst}=$ PROD\&VType $=P Q D \& R Q T=309 \&$ VName $=P Q D \& T S=1246860441 \&$ clientld $=27625$.

Gokçe, F., 2009, 'Behavior of Turkish elementary school principals in the change process: $\mathrm{An}$ analysis of the perceptions of both teachers and school principals', Educationa Management Administration \& Leadership, 37(2), 198-215.

Gruenert, S., 2008, School culture: School climate: They are not the same', Principal issue number (March/April), 56-59.

Hale, E.L. \& Moorman, H.N., 2003, 'Preparing school principals: A national perspective on policy and programme innovations', viewed 05 July 2009 , from http://www.iel. org/pubs/PreparingSchool Principals.html.

Hammersley-Fletcher, L. \& Brundrett, M., 2005, 'Leaders on leadership: The impressions of primary school head teachers and subject leaders', School Leadership and Management 25(1), 59-75.

Harper, D., 2008, 'What's new visually?', in N.K. Denzin \& Y.S. Lincoln (eds.), 3rd edn. Collecting and interpreting qualitative materials, pp. 185-204, Sage, Thousand Oaks.

Harrington, C.E. \& Schibik, T.J., 2003, 'Reflexive photography as an alternative method of the study of freshman year experience', Journal of Student Affairs Research and Practice 41(1), 23-40.

Hattingh, L., 1991, 'n Teorie van Waardes. Ongepubliseerde D.Ed-tesis, Randse Afrikaanse Universiteit.

Hess, F.M. \& Kelly, A.P., 2005, 'Learning to lead? What gets taught in principal preparation programmes', viewed 05 July 2006, from http://www.ksg.harvard. edu/pepg/PDF/Papers/Hess_Kelly_Learning_to_Lead_PEPG05.02.pdf.

Howley, A. \& Howley, C., 2007, Thinking about schools: New schools and innovative practice, Lawrence Erlbaum Associates, Mahwah.

Hoy, W.K. \& Smith, P.A., 2007, 'Influence: A key to successful leadership', International Journal of Educational Management 21(2), 158-167.

Jabal, E., 2006, 'Learning from Hong Kong alumni: Lessons for school leadership', International Journal of Leadership in Education 9(1), 21-44.

Jansen C.A., 2002, 'The organisational culture of the school', in P.C. Van der Westhuizen (ed.), Schools as organisations, pp. 119-145, Van Schaik, Pretoria.

Kassissieh, J. \& Barton, R., 2009, 'The top priority teacher leadership', Principal Leadership (High school edition) 9(7), 22-26, viewed 22 June 2009, from http://0proquest.umi.oasis.ac.za/pqdweb?index $=2 \&$ did $=1663258271 \&$ Src .

Kok, J.C. \& Van der Merwe, M.P., 2002, 'Invitational education: Adding uniqueness - An empirical study', Paper presented at the 18th International Conference of the International Association of Invitational Education, Kennesaw State College, Atlanta, United States of America: 10-12th October 2002.

Kruger, A.G., 2003, 'Cultivating a culture of learning and teaching', in I. Van Deventer \& A.G. Kruger (eds.), An educator's guide to school management skills, pp. 3-13, Van Schaik, Pretoria.

Marcoulides, G.A., Heck, R.H. \& Papanastasiou, C., 2005, 'Student perceptions of school culture and achievement: Testing the invariance of a model', International Journal of Educational Management 19(2), 140-152.

McClay, M. \& Brown, M., 2003, 'Using the concept mapping to evaluate the training of primary school leaders', International Journal of Leadership in Education 6(1) 73-87.

McKerrow, K., Dunn, R. \& Killian, J., 2003, 'Beyond the turf wars: Collaboration in preparing school leaders', Education Leadership Review 4(1), 1-10. 
McMillan, J. H. \& Schumacher, S., 2006, Research in Education. Evidence-based Inquiry, 6th edn., Pearson Education, Boston.

Osterman, K.F. \& Kottkamp, R.B., 2004, Reflective practice for educators: Professional development to improve student learning, Corwin Press, Thousand Oaks.

Pankake, A.M. \& Moller, G., 2003, 'Overview of professional learning communities', in J.B. Huffman \& K.K. Hipp (eds.), pp. 1-12, Schools as professional learning communities, Scarecrow Education, Lanham.

Paton, C., 2006, 'Education in crisis: A lot to learn', Financial Mail, 08 September, p. 1.

Purkey, W.W. \& Aspy, D., 2003, 'Overcoming tough challenges: An invitational theory of practice for humanistic psychology', Journal of Humanistic Psychology 43(2), 146-155.

Retna, K.S., 2007, 'The learning organization: A school's journey towards critical and creative thinking', viewed 14 August 2008, from http://www.d/su.ed.ph/research/ journals/taper/pdf/200706/retna.pdf.

Richardson, V., 2003, 'The dilemmas of professional development', Phi Delta Kappa, 84(5), 401-406.

Riner, P.S., 2003, 'The intimate relationship of invitational education and effective classroom management', Journal of Invitational Theory and Practice 9, 41-56.

Schein, E.H., 1990, “Organizational culture', American Pshychologist 45(2), 109-119.

Schmidt, J.J., 2004, 'Diversity and invitational theory and practice', Journal of Invitational Theory and Practice 10, 26-45.

Schoen, L.T. \& Teddle, C., 2008, 'A new model of school culture: A response to a call for conceptual clarity', School Effectiveness and School Improvement 19(2), 129-153.

School climate research summary, 2007, viewed 21 September 2009, from http:// nscc.csee.net/effective/school_climate_research_summary.pdf

School climate and learning, 2004, Best Practices Briefs 31, 1-10, viewed 21 September 2009, from http://outreach.msu.edu/bpbriefs/issues/brief31.pdf

Schulze, S., 2007, 'The usefulness of reflexive photography for qualitative research: A case study in higher education', South African Journal of Higher Education 21(5) 536-553.

Senge, P., 1990, The fifth discipline, Doubleday, New York.

Smith, C. \& Gillespie, M., 2007, 'Research on professional development and teacher change: Implications for adult basic education', viewed 6 October 2009, from http://www.ncsall.net/fileadmin/resources/ann_rev/smith-gillespie-07.pdf.

Southworth, G. \& Du Quesnay, H., 2005, 'School leadership and system leadership: Essays', The Educational Forum 69(2), 212-220.

Sparks, D., 2003, 'Change agent', Journal of Staff Development 24(1), 55-59.

Sternberg, R.J., 2005, 'A model of educational leadership: Wisdom, intelligence, and creativity, synthesized', International Journal of Leadership in Education 8(4), 347-364

Steyn, G.M., 1994, 'Die sigbaarheid van die skoolhoof as bestuursbenadering: 'n Gevallestudie', Onderwysbulletin XXXVIII(2), 16-31.
Steyn, T., 2006, 'Sustaining an inviting culture in a South African school: A case study', Journal of Educational Studies 5(1), 1-15.

Steyn, G.M., 2007, 'Adhering to the assumptions of invitational education: A case study', South African Journal of Education 27(2), 265-281.

Steyn, G.M., 2009, 'Teacher's perceptions of the provision of continuing professional development programmes in South Africa: A qualitative study', Acta Academica 41(3), 115-137.

Steyn, G.M., 2010, "n Skoolhoof se perspektief op professionele ontwikkeling: 'n enkele gevallestudie', Tydskrif vir Geesteswetenskappe 50(2), 244-261.

Sullivan, S. \& Glanz, J., 2006, Building effective learning communities: Strategies for leadership, learning and collaboration, Corwin Press, Thousand Oaks.

The principals' partnership, 2006, School climate, Research brief, viewed 21 September 2009, from http://www.principalspartnership.com.school climate.pdf

Theory of action: Theory-in-use and espoused theory n.d., viewed 05 May 2011, from http://www.lopn.net/TheoryofAction.html.

Van der Walt, J. L., Potgieter, F. J., \& Wolhuter, C. C., 2010, 'Positiewe Dissipline in die Hande van die Opvoeder', Tydskrif vir Christelike Wetenskap 46(1 (special issue), 145-168.

Van der Westhuizen, P.C., Oosthuizen, I.J. \& Wolhuter, C.C., 2008, 'The relation between an effective organizational culture and student discipline in a boarding school', Education and Urban Society 40(2), 205-224.

Vemić, J., 2007, 'Employee training and development and the learning organization', Economics and Organization 4(2), 209-216.

Vick, R.C., 2004, 'The use of SREB Leadership development framework in pre-service preparation programs: a qualitative study', PhD Dissertation, Department of Educational Leadership and Policy Analysis, East Tennessee State University, viewed 21 September 2009, http://etd-submit.etsu.edu/etd/theses/available/ etd-0809104-151312/unrestricted/VickR081904f.pdf.

Weindling, D., 2003, 'Leadership development in practice: Trends and innovation' viewed 21 September 2009, from http://www.ncl.org/uk/media/1D4/DD/leadershipdevelopment-in-practice-trends-and-innovations.pdf

Wenger, E., 2000, 'Communities of practice and social learning systems', Organization, SAGE Social Science Collection 7(2), 225-246. 7(2), 225-246.

Wenger, E., 2001, 'Organically grown', Training and Development 55(6), 40-41.

Wenger, E., 2007, 'Communities of practice', paper presented at the Third Annual National Qualifications Framework Colloqium, Velmore Conference Estate, 05 June.

Werner, A., 2003, 'Organisational culture, ethics and diversity in a global environment', in $\mathrm{H}$. Schultz, J. Bagraim, T. Potgieter, C. Viedge \& A. Werner (eds.), Organisationa Behaviour: A contemporary South African Perspective, pp. 22-36, Van Schaik, Pretoria.

Zenkov, K. \& Harmon, J., 2009, 'Picturing a writing process: Photovoice and teaching 